\title{
Brasil e Uruguai: influências e aproximações no campo intelectual educacional
}

\author{
Brazil and Uruguay: influences and approximations in the education intellectual field \\ Brasil y Uruguay: influencias y aproximaciones en el campo intelectual educacional
}

\author{
EDUARDO ARRIADA* \\ CAROLINE BRAGA MiCHEL** \\ GABRIELA MEDEIROS NOGUEIRA***
}

\begin{abstract}
RESUMO
No Brasil, nos anos finais do século XIX, como nas primeiras décadas do XX, é possível evidenciar aproximações com os modelos internacionais nos mais diversos campos: econômico, social, político, cultural, educacional. Considerando que muitos intelectuais de Pelotas tiveram um papel ativo na divulgação de um ideário educacional na cidade, tem-se como objetivo neste texto discutir os itinerários de formação desses intelectuais, as redes de sociabilidades que engendraram suas projeções, bem como a influência que receberam de autores uruguaios. Cabe salientar que, pautados no campo da história da educação, compreende-se como intelectual o sujeito que das mais variadas formas preocupava-se em divulgar, discutir e propor projetos educacionais, seja por meio de redes de sociabilidades, seja por conferências, cursos, artigos jornalísticos. Para tanto, foram pesquisados elementos das trajetórias desses intelectuais a partir do acesso de diversos exemplares que compunham seus acervos.
\end{abstract}

$\diamond$

Palavras-chave: História da educação. Uruguai. Pelotas (Rio Grande do Sul). Intelectuais.

\begin{abstract}
An approximation to international models in several fields, such as economic, social, political, cultural and educational ones, occurred in Brazil at the end of the 19th century and in the first decades of the 20th century. Taking into account that many scholars from Pelotas played an active role in the dissemination of educational principles in the city, this study aims at discussing these scholars' educational processes, the social networks which led to their acknowledgement and the influence of Uruguayan authors on their education. It should be highlighted that, based on History of Education, this study considers scholars the ones who have struggled to disseminate, discuss and propose educational projects either by social networks or by conferences, courses and articles. In order to reach its objective, this study followed the scholars' paths by accessing several texts that composed their libraries.
\end{abstract}

Keywords: History of education. Uruguay. Pelotas (Rio Grande do Sul). Brazil. Scholars.

\section{RESUMEN}

El Brasil de los años finales del Siglo XIX, como en las primeras décadas del XX, es posible reconocer aproximaciones a los modelos internacionales en los más diversos campos: económico, social, político, cultural y educativo. Al considerar que muchos intelectuales de Pelotas tuvieron un papel activo en la difusión de un ideario educativo en la ciudad, tenemos como objetivo en este texto discutir los recorridos de formación de esos intelectuales, las redes de socialización que fueron la base de su proyección como intelectuales, así como la influencia de autores uruguayos en su formación. Cabe señalar que, dentro del campo de estudio de la historia de la educación, consideramos como intelectuales a los sujetos que, de las formas más variadas, se interesaron en divulgar, discutir y proponer proyectos educativos, sea a través de redes de socialización o de conferencias, cursos y publicaciones. Por lo tanto, localizamos elementos de las trayectorias de esos intelectuales a partir del acceso de diversos ejemplares que componían sus acervos.

Palabras-clave: Historia de la educación. Uruguay. Pelotas (Rio Grande del Sur). Intelectuales.

\footnotetext{
* Doutor em Educação. Professor no Programa de Pós-Graduação em Educação da Universidade Federal de Pelotas. Integrante do Centro de Estudos e Investigações em História da Educação (CEIHE/FaE/UFPEL). Coordenador do Centro de Documentação (CeDOC/CEIHE/UFPEL). <https://orcid. org/0000-0001-5216-2739>. E-mail:<earriada@hotmail.com>.

** Doutora em Educação pela Universidade Federal de Pelotas. Pós-Doutoranda em Educação na mesma Universidade. Integrante do Centro de Estudos e Investigações em História da Educação (CEIHE/FaE/UFPEL) e do Grupo de Pesquisa em História da Alfabetização, Leitura, Escrita e dos Livros Escolares (Hisales) da UFPel.<http://orcid.org/0000-0002-6171-4125>. E-mail: <caroli_brga@yahoo.com.br>.

*** Doutora em Educação. Professora da Universidade Federal do Rio Grande (FURG). Integrante do Núcleo de Estudo e Pesquisa em Educação de Zero a Seis anos (Nepe/IE/Furg) e do Grupo de Pesquisa História da Alfabetização, Leitura e Escrita e dos Livros Escolares (Hisales) da UFPel. ORCID iD: $<$ http://orcid.org/0000-0002-6985-064X>. E-mail: <gabynogueira@me.com>.
} 


\section{INTRODUÇÃO}

Neste texto, tem-se por objetivo discutir os itinerários de formação dos intelectuais de Pelotas (RS), as redes de sociabilidade que engendraram suas projeções e seus envolvimentos com diversas instituições, assim como a influência de autores uruguaios nas suas formações e trajetórias.

É importante frisar que, nos últimos anos, surgiram diversos estudos para além de categorias consagradas no campo da história da educação, como, por exemplo, cultura escolar, disciplinas escolares, livro didático, arquitetura escolar, viagens pedagógicas. Observa-se o retorno de "velhas" categorias, muitas delas contempladas em outros campos do saber, como a sociologia. Assim, a categoria intelectual é retomada no presente artigo como escopo para investigar as redes de sociabilidade de alguns intelectuais de Pelotas e seus itinerários de formação (MARLETTI, 1992; VIEIRA, 2011). Para tanto, aspectos da trajetória de alguns desses intelectuais foram localizados a partir do acesso de diversos exemplares que compunham seus acervos. Essas obras foram, ao longo dos anos, adquiridas em diversos sebos da cidade, após a venda e/ou descarte de partes das suas bibliotecas ${ }^{1}$. Sua identificação foi possível pelo fato de os exemplares terem a assinatura e/ou o carimbo do antigo proprietário.

A análise do material proposta neste artigo contemplou três intelectuais: João Simões Lopes Neto, Fernando Luís Osório e Joaquim Augusto Assumpção Júnior. Todos com fortes vínculos com a cultura uruguaia, além de marcante atividade pedagógico-cívica na cidade de Pelotas.

Em sua estrutura geral, a abordagem metodológica adotada encontra-se alicerçada na pesquisa bibliográfica, tendo em alguns momentos uma preocupação centrada na análise documental, caso, por exemplo, do diário de Humberto de Campos e a memória "Pelotas de Agora", de Abadie Farias Rosa. Documentos que foram utilizados ao longo do estudo, tais como textos autobiográficos, diários íntimos, correspondências, documentos de famílias, podem ser categorizados, a partir da perspectiva de Cellard (2010), como documentos pessoais.

Quanto ao contexto do período investigado, cabe salientar que na consolidação do Estado Nacional Brasileiro, estruturada nos anos finais do século XIX, bem como nas primeiras décadas do século XX, é possível evidenciar diversas aproximações com os modelos internacionais nos mais diversos campos: econômico, social, político, cultural, educacional. No âmbito educacional, esse aspecto é perceptível no estabelecimento de diversos educandários; na constituição de missões de

\footnotetext{
${ }^{1}$ As referidas obras encontram-se localizadas no Centro de Documentação $(\mathrm{Cedoc})$, vinculado à Universidade Federal de Pelotas.
}

estudos; na legislação educacional; no uso de manuais pedagógicos e didáticos (tanto em língua estrangeira, e/ou adaptados, ou ainda traduzidos); nos materiais didáticos; nos métodos de ensino; nas teorias educacionais; assim como na divulgação de autores pelos mais diversos tipos de informações, sejam conferências, palestras, publicação de artigos em periódicos, edição de livros.

No período republicano, essa prática teve continuidade, particularmente, por ocasião das reformas de inspiração escolanovista, nos anos 20 e 30 do século $\mathrm{XX}$, com uma busca constante em operar mudanças na educação nacional, tendo como parâmetro experiências realizadas no estrangeiro. Diversos educadores, e muitos dos reformadores, utilizaram diferentes estratégias para se aproximar do que havia de mais moderno em termos de educação. A própria Associação Brasileira de Educação, criada em 1924, com o intuito de dar visibilidade à grande causa da educação nacional, promoveu conferências, palestras e cursos, editou revistas e manteve correspondência com educadores de diversas nacionalidades. Prédios escolares, livros didáticos, bibliotecas, mobiliários, métodos de ensino, povoavam essas iniciativas e não escaparam das atenções de todos aqueles que buscavam respostas para romper com o atraso no qual julgavam se encontrar o país, cujo sistema educacional estava, nessa representação, em completa desestruturação (MIGNOT; GONDRA, 2007).

O Rio Grande do Sul não estava alheio a essa prática. No ano de 1909, com a criação dos colégios elementares, um modelo novo de escola primária começava a ser erguido, substituindo as "velhas e arcaicas" escolas elementares, que funcionavam em uma única sala de aula, tendo apenas um único professor (PERES, 2010). $\mathrm{Na}$ busca por qualificar o professorado rio-grandense e melhorar as condições estruturais da educação do Estado, as autoridades republicanas discutiam a importância de enviar missões ao exterior, particularmente à Europa e/ ou aos Estados Unidos. Diante do custo, e dentro de um princípio de contenção de despesas, consideraram que enviar uma missão ao país vizinho, no caso o Uruguai, seria salutar, sendo as razões indicadas: proximidade territorial, o que evitava altos custos; língua similar ao português, o que facilitava a compreensão e o diálogo; além do reconhecimento da excelência da educação no Uruguai (MICHEL; ARRIADA, 2013).

O Estado, então, durante a administração de Borges de Medeiros, teve a iniciativa, em 1913, de enviar ao Uruguai uma missão de estudos na busca de modernização, ou seja, na tentativa de reorganizar o ensino primário, com novos métodos, com um corpo docente disciplinado e competente. Dentre os objetivos dessa missão, destaca-se o intuito de realizar estudos sobre a estrutura e funcionamento do sistema escolar, 
mais particularmente sobre o ensino primário. Para tanto, o governo do Rio Grande do Sul constituiu um grupo de educadores, liderados por Alfredo Clemente Pinto (diretor da Escola Complementar), além de Affonso Guerreiro Lima, Ondina Godoy Gomes, Georgina Godoy Moritz, Marieta de Freitas Chaves e Florinda Tubino.

O país vizinho, a República Oriental do Uruguai, nas primeiras décadas do século XX, era considerado por diversas nações como um possível modelo a ser investigado e, quiçá, até imitado. Os avanços e progressos renderam ao país nesse período o status de "Suíça latino-americana". Desse modo, era comum intelectuais brasileiros periodicamente visitarem o Uruguai. Essa prática era realizada desde o final do século XIX, e se acentuou nos primeiros anos do século XX. Um dos intelectuais brasileiros que rotineiramente não apenas visitava, mas também permanecia várias semanas no Uruguai, era Gaspar da Silveira Martins.

Buscando conhecer esse contexto, um grupo de intelectuais do Rio de Janeiro dirigiu-se ao Uruguai em 30 de outubro de 1931. A viagem a Montevidéu estava sob a responsabilidade de Belisario Penna, ocupante interino da pasta do Ministério da Educação e Saúde, que em cumprimento ao decreto presidencial assinado pelos dois países tinha a finalidade de promover "o intercâmbio de professores e alunos ou qualquer outro ato de aproximação espiritual entre estes dois países"2.

Denominada "Embaixada de Intercâmbio Intelectual", seu financiamento era oriundo de recursos provenientes de parte da dívida do governo uruguaio com o governo brasileiro para a construção da ponte internacional de Jaguarão. O grupo estava constituído dos seguintes intelectuais: Armanda Álvaro Alberto, membro do Conselho Diretor da Associação Brasileira de Educação (ABE); Mello Leitão, professor do Museu Nacional e da Escola Normal; Ernani Lopez, professor universitário e presidente da Liga de Higiene Mental; Renato Pacheco, presidente da Confederação Brasileira de Desporto; Rosalina Coelho Lisboa Miller, escritora e poetisa; e Humberto de Campos, presidente da Academia Brasileira de Letras. A finalidade precípua era proferir palestras no país vizinho e, ao final, apresentar um relatório sobre as atividades realizadas no âmbito do ensino primário, secundário, superior, educação física, vida associativa e jornalismo (MIGNOT, 2010). Um dos integrantes, Humberto de Campos, deixou em suas memórias pormenorizado relato de sua estadia em Montevidéu, conforme é possível observar nos seguintes fragmentos:

\footnotetext{
2 Decreto assinado em 16 de junho de 1931 pelo presidente Getúlio Vargas e por seus ministros da Educação, Afrânio de Mello e Franco e Francisco Campos.
}

[...] Eu meti as minhas notas no bolso e, em companhia dos colegas de embaixada intelectual, e do ministro do Brasil, pus o pé direito, e amigo, no cais molhado e deserto da invicta Montevidéu.

O Uruguai, mais do que a Argentina, é um país macrocéfalo. É mesmo, em todo o mundo, aquele cuja cabeça está em maior desproporção com o corpo. Avaliada em 1.900 .000 a população da República (o recenseamento de 31 de dezembro de 1928 acusou 1.808.286), possui Montevidéu cerca de 650.000, isto é, mais da terça parte dessa população. O progresso da cidade, a sua riqueza, a intensidade do seu comércio, as múltiplas manifestações, em suma, da sua vitalidade econômica, oferecem o índice admirável de uma espantosa atividade rural. Nenhum povo pequeno, em todo o planeta, sustenta, relativamente, cidade tão populosa e tão farta (CAMPOS, 1962, p. 230-231).

No entendimento de Humberto de Campos, apesar de Montevidéu monopolizar toda a vida econômica e cultural do Uruguai, este não deixava de ser mesmo assim um país progressista, com forte vitalidade econômica que se refletia em um bem-estar, e na "mais perfeita democracia da América", decorrência em parte do governo liberalizante de Batlle y Ordónez. ${ }^{3}$ Como se pode observar em suas memórias:

[...] Montevidéu é, finalmente, uma cidade rica, irrigada por todo o ouro do país. O nosso melhor comércio de modas mesmo, o da Avenida Central ${ }^{4}$ e circunjacências, nada tem de superior (CAMPOS, 1962, p. 233).

O Uruguai deve ser considerado, hoje, a mais perfeita democracia da América. Com uma superfície equivalente à do nosso Estado do Paraná e uma população inferior à do Estado do Rio de Janeiro, a sua organização política foi rápida e fácil. Data, esta, de 1919, isto é, do governo Feliciano Vieira, quando, após uma viagem à Europa, onde estudara os diversos sistemas de governo, Batlle y Ordonez resolveu dar à sua pátria uma Constituição mais de acordo com as suas condições étnicas e geográficas (CAMPOS, 1962, p. 239).

Diversas minúcias, revelando outras facetas de Montevidéu, são descritas pelo intelectual brasileiro. Embora com certos equívocos e/ou exageros, além de certo desconhecimento da realidade do Uruguai, importa salientar que existia no contexto da época uma forte crença da existência de uma democracia consolidada no Uruguai. Também era voz corrente que as suas diversas instituições (e aqui incluindo a educação) eram modelos a serem seguidos.

\footnotetext{
${ }^{3}$ Nasceu em Montevidéu. Formado em Direito, foi político e jornalista. Em 1886, fundou o diário El Dia e foi chefe político da província de Minas (1887), deputado pela província de Salto (1890-1893) e senador de Montevidéu (1899-1902) (SOUZA, 2003).

${ }^{4}$ Refere-se ao Rio de Janeiro.
} 
Essa realidade progressista, arejada, democrática e vanguardista (verdadeira ou não) influenciava profundamente diversos intelectuais brasileiros. Muitos deles observavam os debates, as transformações que ocorriam, fossem no âmbito político ou cultural; visitavam assiduamente o Uruguai; acompanhavam as publicações em periódicos e livros produzidos por escritores do país vizinho, particularmente as obras de Carlos Vaz Ferreira, Orestes Araújo, José Enrique Rodó, Florencio Sánchez, entre outros.

Nesse contexto, entende-se que diversos intelectuais de Pelotas tiveram um papel ativo na divulgação de um ideário educacional na cidade. Buscando contextualizar e sustentar essa afirmação, organiza-se o texto em três seções. Na primeira, com a finalidade de compreensão da realidade sociocultural do Uruguai, elabora-se uma síntese de sua formação, salientando particularmente a administração de Batlle y Ordónez, que teve um papel fundamental no processo de modernização, transformando um pequeno país rural, oligárquico, violento e atrasado numa próspera, progressista e democrática nação. $\mathrm{Na}$ segunda seção, procura-se caracterizar a cidade de Pelotas, destacando como a mesma implementou medidas progressistas, mormente em relação à educação. Para além desse aspecto, uma modernidade indicava o alto grau de urbanização, um parque industrial constituído, teatros, cafés, editoras, demonstrando o elevado nível de escolarização. Na última seção, trata-se do papel dos intelectuais, em uma concepção mais ampla desse termo, identificando alguns destes no contexto de Pelotas, bem como os autores uruguaios por eles utilizados.

\section{O CONTEXTO URUGUAIO}

Impulsionado pelo governo de José Batlle y Ordónez, o Uruguai mostrou significativos avanços nas primeiras décadas do século XX, passando cada vez mais a ter um papel de destaque na América Latina. Esse governo se expressava em uma atitude paternalista, assim como atuava como mediador nos intensos conflitos sociais que se produziam nesse início de século, enfrentamentos de trabalhadores e classe patronal, além de ser também impulsionador de um desenvolvimento industrial voltado para a substituição das importações. Dois foram os mandatos de José Batlle y Ordónez, o primeiro, de 19031907, e o segundo, de 1911-1915. Enquanto dirigente, teve a percepção de imprimir reformas profundas, dando margem à ascensão de novas forças sociais, entre elas a classe média urbana da capital, e ao proletariado que começava a se organizar (CAETANO, 2011; NAHUM, 2013).

Seu programa de reformas pautava-se, basicamente, nas seguintes premissas: a crença de que a principal função do Estado era promover a justiça social e a tranquilidade política; a defesa do plebiscito por acreditar que o povo representava a única fonte de poder político; e a liberdade de consciência através da separação entre Estado e Igreja (SOUZA, 2003). Portanto, a política e a educação eram vistas como os principais veículos de produção de uma "identidade nacional".

As reformas implementadas oportunizaram a base para a modernização do país. Dentre estas, destacam-se: o fortalecimento do Estado com o aumento do número de ministérios; a criação do Ministério de Indústria e Obras Públicas, em 1907; a criação do Supremo Tribunal de Justiça nesse mesmo ano; em 1911, o Ministério da Instrução Pública; a limitação do poder da Igreja, com aprovação de leis liberais, tais como o divórcio; e a introdução, em 1912, de leis protecionistas limitando e controlando a entrada do capital estrangeiro. Em relação às questões trabalhistas, o Estado assumia o papel de conciliador entre as classes, intervindo mediante uma legislação protetora ou com garantias efetivas de direito de sindicalização.

No plano social, houve um crescimento vegetativo da população, assim como uma acelerada taxa de urbanização. No último quarto do século XIX, a população duplicou, passando de 500 mil habitantes para 1 milhão, e no primeiro quarto do século $\mathrm{XX}$ atinge a cifra de 1,5 milhão. Quase um terço dessa população vivia em Montevidéu, que no início do século XX aumentou de 34 mil para 270 mil (PALOMEQUE, 2012). Parte desse aumento populacional foi decorrente dos fluxos migratórios ocasionados pela primeira guerra mundial (ODDONE, 2008; CAETANO, 2011; NAHUM, 2013).

Por sua vez, no plano cultural e educacional, uma forte mudança foi a expansão do sistema público de ensino, que chegou a abarcar quase a totalidade da população. Como exemplos dos feitos nesse campo, citam-se: a criação do Instituto Surdo-Mudo, em 1909; em 1912, a criação de escolas secundárias departamentais e o livre acesso, em 1916, ao ensino secundário e superior; e a criação da universidade para a mulher, em 1912 (DEVOTO, 1956, p.479). Esses aspectos, unidos a um relativo bem-estar econômico, deu lugar ao surgimento de uma classe média que desempenharia um forte papel de cobrança relativo ao papel do Estado.

Especificamente ao ensino primário, destaca-se que o crescimento da população escolar passou de 45.617 matriculados, em 1897, a 74.717, em 1910, atingindo 157.300 no ano de 1930. O número de escolas para atender a essa população escolar cresceu também, desde 545 escolas, em 1897, a 1.100 escolas no ano de 1930. O número de professores também era significativo, de 2.300, em 1910, passou a 3.600 em 1930 (BRALICH, 1987, p. 80). Salienta-se, também, que, nas primeiras 
décadas do século XX, políticas de supressão do ensino religioso nas escolas foram realizadas pelo Estado, fato consubstanciado pela Lei de 6 de abril de 1909, disposição que se enquadra no plano de laicização do Estado.

A confrontação entre a Igreja e o Estado pela ocupação de novos espaços públicos, durante as últimas décadas do século XIX e as primeiras décadas do século XX, alcançou um limite pontual em 1919, com a separação institucional de ambas. Contudo, essa solução política não fechou a questão religiosa no Uruguai. Ao contrário, vários temas continuaram sendo motivo de debates, ficaram como contas não resolvidas do processo de secularização, questões que nenhuma das partes estava disposta a ceder. Um desses temas foi precisamente o da educação.

Nas primeiras décadas do século XX, as lideranças educativas do Uruguai, capitaneadas pelo inspetor nacional da Instrução Primária, Dr. Abel J. Pérez, compreendiam que a base fundamental de toda educação estava alicerçada na escola, e, para que se tivesse qualidade na mesma, fazia-se necessário ter "bons" professores. Para tanto, algumas estratégias complementares à formação de professores oferecidas nos Institutos Normal de Señoritas $e$ de Varones foram adotadas, como, por exemplo, a ampliação e disseminação, a partir de 1903, das Conferências $^{5}$ (onde Carlos Vaz Ferreira desempenhou um papel relevante) e a edição e publicação dos Anales de Instrución Primária, revista em que era transcrita a maior parte das conferências realizadas. Esta se constituiu em um veículo formador de compreensões e de práticas pedagógicas por contribuir e fomentar um debate pedagógico no Uruguai.

Ainda com a intenção de afirmar perante a sociedade a importância e a qualidade da formação estatal despendida pelo Estado, alguns intelectuais do Uruguai salientavam:

[...] a organización de los dos Institutos, el de señoritas y el de varones, que hacen las veces de Escuelas Normales, distribuyendo lo mejor que fue posible las materias de estudio, reorganizando el modo cómo sus alumnos deben hacer la práctica en las Escuelas de Aplicación, modificando ligeramente los programas, elevando á tres la cantidad de años de estudio que se necesitan para obtener el título de Maestro de primer grado [...] (ARAÚJO, 1911, p. 506).

O processo estatal da educação resultava em fortes investimentos na formação de um corpo docente qualificado e, por consequência, na elevação geral da qualidade do ensino. Cabe ressaltar que grande parte desses investimentos estava voltada para o ensino primário. Por meio de construção de escolas, melhor

\footnotetext{
5 As conferências eram destinadas aos professores, com o intuito de criar uma unidade nos discursos e práticas desenvolvidos no ensino primário.
}

remuneração dos mestres, investimento em material didático, uma modernidade pedagógica ia aos poucos modificando a velha e arcaica estrutura educacional do país.

As observações recolhidas, a convicção da qualidade do modelo educacional uruguaio, além de uma estrutura e funcionamento eficiente das escolas primárias, estabeleceram a convicção das lideranças do Rio Grande do Sul na relevância de conhecer e aproximar-se do Uruguai, resultando em ganhos para o Estado.

\section{O CONTEXTo BRASIleiro (PElotas/RS)}

Nas primeiras décadas do século XX, o processo de escolarização da sociedade brasileira atingia certos patamares elevados em relação ao contexto educacional do século XIX. Segundo Nagle (2001), em 1922 estavam matriculados 1.030 .752 alunos nas escolas primárias, representando $29 \%$ da população escolar. Esses índices estavam intrinsicamente vinculados às propostas governamentais, principalmente dos governos estaduais, mas com parcela significativa de participação das autoridades municipais e da iniciativa particular. Em 1933, a matrícula no ensino primário no Brasil atingia o efetivo de 1.918 .090 alunos, assim distribuídos: 63,46\% na rede estadual, $19,97 \%$ na rede municipal e $16,55 \%$ na rede particular (SOUZA, 2008, p. 48).

O estabelecimento da República não apenas alterou a forma de governo, como implementou novas mentalidades. Cada vez mais, o ideário liberal e modernizante se fazia presente, ocupando a educação um papel relevante, em especial a escola primária. Destinada pelo princípio constitucional da "obrigatoriedade", tinha o papel de difundir os saberes elementares (ler, escrever e contar), os rudimentos das ciências (geografia, física, química, etc.) e o cultivo do civismo (instrução moral e cívica, ginástica, higiene).

Os elementos da modernização cada vez mais estavam atuantes, se em um primeiro momento nas principais capitais e cidades maiores, logo se espraiava por cidades de porte médio, caso de Pelotas, e com certeza de diversas outras cidades do Brasil. Modernidade que se refletia em um acentuado processo de urbanização, aparecimento de indústrias, crescimento populacional, surgimento de bairros, abertura e/ou alargamento de ruas, ajardinamento das cidades (praças, arborização, jardins públicos), iluminação elétrica, meios de transportes públicos, proletarização de parcela da população, entre outras iniciativas. Paralelamente a esse processo, a escola caracterizava-se como um dos elementos essenciais.

No regime republicano, no Brasil, a escola cumpriu o desiderato de ser porta-voz dessas novas políticas. Os professores, assim como os alunos, eram agentes 
propagadores de um ideário calcado no positivismo, no qual ordem e progresso eram lema e bandeira. Os diversos governos, tanto na esfera federal, estadual, como municipal, por meio de dispositivos legais, incorporavam as ideias liberais, ou seja, obrigatoriedade, gratuidade e laicidade do ensino primário. Introdução de novos métodos de ensino, como o intuitivo; a criação de estabelecimentos próprios para o ensino, como os grupos escolares; o serviço de inspeção técnica nas escolas, surgindo a figura do inspetor de ensino, etc.

Assim, a escola, para os republicanos, cumpria o papel de viabilidade da instauração da nova ordem, agente preponderante para alavancar o progresso e superar as mazelas do analfabetismo, pobreza e miserabilidade de grande parte da população brasileira. Na sociedade excludente que vigorava nos fins do século XIX e início do século $\mathrm{XX}$ ou, melhor dizendo (crítica construída particularmente pelos elementos mais radicais das hordas republicanas), sociedade monárquica, o acesso à educação era apanágio de poucos. Como consequência, a escola passa a ser uma arma para debelar e superar as amarras do atraso, para então ser possível ao país caminhar na senda do progresso. Mas, ao mesmo tempo, passa a ser considerada "arma perigosa", exigindo a redefinição de seu estatuto como instrumento de dominação (CARVALHO, 1989).

Em várias cidades brasileiras, as autoridades municipais tentavam acompanhar os discursos e práticas estabelecidos nos grandes centros; do mesmo modo, a cidade de Pelotas buscava estar de acordo com os movimentos, dispositivos e novas determinações em relação à educação. No tocante à renovação pedagógica, a introdução de novos métodos de ensino, em especial a adoção do método intuitivo; a reconfiguração do espaço escolar, isto é, a construção de prédios adequados para o ensino, bem como o fornecimento de mobiliário e material didático; introdução de um novo currículo, indo além do simples "ler, contar, escrever", com novas disciplinas introduzidas (lição de coisas, música, educação física, educação cívica), entre outras.

Desse modo, Pelotas sofreu uma série de transformações decorrentes da consolidação de relações capitalistas. O ciclo do charque e, posteriormente, o processo de substituição da mão de obra escrava pelo trabalho assalariado propiciou uma grande concentração de capitais que se refletiram na incipiente, mas gradual industrialização e urbanização.

Apesar dessas circunstâncias e de seguidas crises, o montante total gerado pelas charqueadas era expressivo, fato que possibilitou uma razoável concentração de capitais, que se refletiu no aparelhamento arquitetônico, urbanístico, artístico e cultural. Uma infraestrutura que dinamizava e ditava novos padrões de comportamentos, particularmente em termos de políticas de gestão públicas evidenciadas pela priorização de quatro grandes alicerces: transporte, iluminação, saneamento e educação.

Uma modernidade em construção pairava no ar, embora lenta e ainda não percebível para uma grande maioria. Mas, atentando para os diversos depoimentos de viajantes, em crônicas de alguns jornalistas, em matérias e anúncios publicados na imprensa da época, percebeuse que um conjunto de novas ideias eram enunciadas, discutidas, aceitas e/ou negadas.

Abadie Farias Rosa (1918, p. 180) foi um deles:

Saí. Saí cedo, para rever a cidade. Certo, há dois anos, quando aqui estivera, depois de uma ausência de quase um lustre, Pelotas já era outra. Impressionara-me aquele súbito avanço. A remodelação ia-se impondo. Estava já quase completa a instalação da rede de esgotos, preparava-se a próxima inauguração dos bondes elétricos, cuidava-se da reforma do calçamento. [...] Em arrabaldes, como no Porto, surgiam fábricas, centro de produção manufatureira, como essa de Fiação e Tecidos. [...] Era assim também nas outras áreas suburbanas da cidade. E era assim também no perímetro central a vida nova. O mercado apresentava-se outro, na elegância dos seus torreões. A ponte de pedra fora reedificada. Ao lado sul do Santa Bárbara havia uma praça ajardinada. [...] É toda uma colossal vitrina de jóias, de pedraria rara [...]. Diante do desdobramento de Pelotas de agora, sentindo a vida nova nos elétricos que passavam velozes, atestando a ideia da pressa e da energia, que são os maiores fatores da vida moderna.

De certo modo, essa modernidade, que aos poucos se consolida, carrega diversas contradições. Certos setores pactuam, concordam e incentivam essa nova maneira de ver e sentir; outros, porém, ainda vinculados ao sistema patriarcal e agrário, opõem-se ferozmente. Diversos intelectuais pelotenses, capitaneados, sobretudo, por jornalistas, advogados, médicos, constroem um discurso enaltecendo a racionalidade e os progressos da ciência. Suas ideias espalham-se por várias esferas do econômico, do social, do cultural, atingindo diversas camadas da sociedade.

Novas formas de socialização floresciam, as ruas passavam a ser locais privilegiados de circulação e contato. Proliferavam cinemas, teatros, cafés, livrarias. As autoridades públicas cada vez mais se ocupavam de organizar esses novos espaços. Medidas higienistas faziam parte do cotidiano, tais como saneamento básico, rede de esgotos, vacinação obrigatória, calçamento das ruas, afastamento das casas de carnes para fora do perímetro urbano, proibição da circulação de animais soltos, etc. Esse conjunto de medidas indicava novas relações de trabalho, de convívio, por muitos denominado "modernização". Pelotas acompanhava as reformas que ocorriam na capital federal, assim como as novidades europeias. 


\section{O PAPEL DOS INTELECTUAIS}

A ideia de intelectual muitas vezes transcende ao que se pode considerar homens que influenciaram a opinião pública. Uma das concepções mais utilizadas designa os intelectuais como uma categoria ou classe social particular, que se distingue pela instrução e pela competência, científica, técnica ou administrativa, superior à média. Paralelamente a esse entendimento, encontra-se frequentemente uma segunda acepção, para a qual intelectuais são os escritores "engajados" com algum projeto político. Por extensão, o termo se aplica também a artistas, estudiosos, cientistas e, em geral, a quem tenha adquirido, com o exercício da cultura, uma autoridade e uma influência nos debates públicos (MARLETTI, 1992, p. 637).

Para este trabalho, utilizaram-se indistintamente as duas acepções. Uma centra-se nos itinerários de formação dos intelectuais de Pelotas, as redes de sociabilidades que engendraram suas projeções e seus envolvimentos com diversas instituições. A outra investiga a influência de autores uruguaios nas suas formações e trajetórias.

Uma contribuição aos estudos dessa natureza advém da abordagem dinâmica da construção e circulação de ideias, projetos e políticas de educação, identificados no entrelaçamento das redes intelectuais que ultrapassam as fronteiras nacionais. Isso rompe com a associação direta entre ideias e indivíduos, colocando um conjunto de problemas relacionados aos itinerários pessoais e coletivos, a ambiência cultural, os constructos intelectuais de época.

Diversos intelectuais de Pelotas, tais como João Simões Lopes Neto, Fernando Luís Osório e Joaquim Augusto Assumpção Júnior, tiveram papel ativo na divulgação de um ideário educacional na cidade, atuando como oradores, professores e autores de livros.

Eles compunham a elite letrada da cidade e tinham como modelo a civilização europeia. No processo de formação da identidade desses intelectuais, as diferenças de classe, etnia, religião, profissão, foram relativizadas em nome de um interesse coletivo. As regras de reconhecimento incluíam credenciais, como diplomas e títulos, além de uma valorização das habilidades retóricas e textuais. Havia por parte da sociedade um reconhecimento da condição de distinção social que advinha do processo de formação, seja por certificação de diplomas, seja por uma autoformação (VIEIRA, 2011).

Em relação à educação, havia uma crença de que somente por meio desta seria possível superar o atraso da cidade. O campo educacional era e permanecia sendo espaço de prática e de intervenção sócia, de ação cívica dirigida a fins práticos e políticos. Nessa chave de leitura, a educação - antes de representar a transmissão da cultura ou a atividade profissional - significava um projeto político-pedagógico (VIEIRA, 2011).
O engajamento, a luta, a preocupação constante desses intelectuais pela melhoria da educação se mantinha tanto na dimensão da crítica à pedagogia tradicional quanto na reformulação do processo de formação dos professores e na organização do sistema público de ensino.

A crença no Estado como agente político capaz de realizar o projeto moderno de reforma social atravessou diferentes gerações de intelectuais. E a presença de mitos da unidade cultural e política da nação e do atraso do país em relação às nações civilizadas no discurso da intelectualidade brasileira foi fundamental para a produção da justificativa do protagonismo do Estado. Nessa chave de leitura, o país necessitaria queimar etapas em seu desenvolvimento, sob pena de ficar eternamente em descompasso com a modernidade (VIEIRA, 2011).

As campanhas de educação cívica representaram um movimento geral das elites pensantes na sociedade brasileira, cuja repercussão se estendeu por todo o território nacional (BORGES, 2009). Dessa preocupação, decorre a busca pela formação cívica através da criação de salas de leitura e bibliotecas voltadas especificamente para constituição de um acervo de civismo.

Um dos autores com forte atuação na sociedade pelotense foi João Simões Lopes Neto. Conforme os necrológios revelam, como destaca Reverbel (1981), Simões Lopes Neto era referido como exímio jornalista, estudioso do folclore, ativo homem de negócios e de grande participação comunitária, ${ }^{6}$ sendo fundador de um Clube de Ciclismo e da Sociedade Protetora dos Animais, e também escritor de tratados de piscicultura. ${ }^{7} \mathrm{O}$ que indicava um destino que mal deixava vislumbrar sua atual consagração literária. No entanto, um aspecto salientado em um dos necrológios chama atenção a despeito do pouco explorado no âmbito biográfico: sua condição de professor e homem ligado às questões educacionais, ${ }^{8}$ reconhecido e admirado por seus contemporâneos. Pinto da Rocha, político e intelectual rio-grandense, assim se manifestou:

\begin{abstract}
Embora educado na carreira do comércio e da indústria, o espírito de João Simões exigia a arena vasta das controvérsias, entrou no jornalismo e triunfou; passou ao teatro e conquistou vitórias; tentou o romance e os seus contos patrícios, fizeram-no respeitado; a polêmica o empregou, a crítica teve na sua pena uma servidora firme e brilhante; a crônica deve-lhes serviços inestimáveis; a burocracia teve nele um funcionário modelo; o magistério encontrou no seu espírito um exemplo carinhoso [...] (ROCHA, 13-07-1916).
\end{abstract}

\footnotetext{
Cf. A Opinião Pública, Pelotas, 15-06-1916.

7 Idem.

8 Nesse mesmo necrológio da Opinião Pública, a despeito de várias impropriedades, tais como ter sido acadêmico de Direito e Engenharia, refere-se à atividade docente do escritor, que foi professor na Escola de Comércio e no Ginásio Pelotense.
} 
Leitor voraz, João Simões Lopes Neto mantinha um permanente contato com revistas e periódicos do Uruguai, caso, por exemplo, da revista Careta, a qual possuía vários exemplares em sua biblioteca. Além da profunda admiração que mantinha por Florêncio Sanchez, conhecido e reputado teatrólogo do país vizinho.

Outro intelectual pelotense foi Joaquim Luís Osório. Em 10 de abril de 1912, ele deixou a presidência do Tiro $31,{ }^{9}$ uma vez que fora eleito deputado federal pelo Rio Grande do Sul, assumindo o vice-presidente Joaquim Assumpção Júnior ${ }^{10}$ (ALMANAQUE DE PELOTAS, 1918, p. 166). Eleito para o próximo mandato, Joaquim Assumpção Júnior exerceu o cargo de janeiro a dezembro de 1915, ausentando-se nos meses de março a outubro, sendo substituído por João Simões Lopes Neto.

Essa rotatividade nos cargos demonstra o grande envolvimento desses sujeitos nas esferas públicas. Muitos eram convidados para assumirem entidades privadas sem fins lucrativos, mas, ao serem eleitos para cargos públicos, eram obrigados a declinar dos convites. Nesses espaços de influência, visibilidade e poder, fortes vínculos eram criados, repercutindo ações e ideias no conjunto da sociedade.

Além de diversas atividades desempenhadas em Pelotas, Joaquim Assumpção teve intensa participação no movimento revolucionário de 1930, que conduziu Getúlio Vargas à presidência do Brasil. No Rio Grande do Sul, com a vitória da Aliança Liberal, foi nomeado interventor federal Flores da Cunha. Estabelecido como governador do Estado, organiza um novo partido, o Partido Republicano Liberal, cujas diretrizes foram traçadas em novembro de 1932, em congresso realizado em Porto Alegre. Neste, as lideranças de Pelotas se fizeram representar por meio do prefeito Augusto Simões Lopes, por Vítor Russomano, José Lucas Martins, Ildefonso Simões Lopes e Joaquim Augusto de Assumpção.

Tendo participação ativa nesse congresso, Joaquim Augusto de Assumpção pactuava com diversas medidas, entre estas: aplicação crescente das rendas públicas ao desenvolvimento do ensino em todos os seus graus; cooperação orçamentária obrigatória da União no ensino primário; uniformização da finalidade básica do ensino

\footnotetext{
${ }^{9}$ O Tiro 31 era uma entidade paramilitar. Essa denominação decorre de ter sido a 31a estabelecida no país. Além de preparar os indivíduos para a prática do tiro, tinha um caráter cívico. Sob o influxo de campanhas patrióticas, das quais foi baluarte Olavo Bilac, foram criadas várias linhas de tiro, estrategicamente localizadas nas cidades maiores de cada região. Vários intelectuais e amigos próximos de Simões Lopes Neto, tais como Januário Coelho da Costa, Fernando Osório e Joaquim Luís Osório, estiveram com ele na fundação, divulgação e administração do Tiro de Guerra 31, em Pelotas. Para mais detalhes, ver: OSORIO, Joaquim Luís (1910)

10 Joaquim Augusto Assumpção Júnior foi diretor do Ginásio Pelotense no período de 1914 a 1917, sendo intendente da cidade de Pelotas em 1933 e 1934.
}

primário gratuito, leigo, vocacional e integral e obrigatório quando possível; educacão religiosa voluntária nas escolas públicas (ALMANAQUE DE PELOTAS, 1933, p. XVII).

Em sua biblioteca, foi possível localizar o seguinte livro: Historia de la escuela uruguaya, por Orestes Araújo, com um prólogo de Dr. D. Abel J. Pérez. Montevideo, Imp. El Siglo Ilustrado de Gregorio V. Mariño, 1911. Nessa obra, consta a assinatura de Joaquim Augusto de Assumpção Júnior, datada de fevereiro de 1914, em Pelotas.

De modo similar, tem-se a figura intelectual de Fernando Luís Osório, ${ }^{11}$ revelando tanto uma certificação formal como em outros aspectos uma faceta estruturada no autodidatismo. Essa última característica é perceptível na amplitude de sua produção intelectual, na qual diversos temas foram explorados pelo autor, tais como civismo, história, política, educação, nacionalismo, ficção, sociologia, etc. Sua vasta biblioteca (mais de 15 mil volumes) denota a preocupação e a permanente busca de uma atualização nas mais diversas áreas do saber.

Em 1916, Fernando Luís Osório foi eleito presidente do Tiro 31. Na sua posse, conclamava os sócios "[...] a marcharem na mesma fileira, pela exaltação do patriotismo, fé consciente, visão objetiva, brilhante e fecunda atividade [...]" (ALMANAQUE DE PELOTAS, 1916). Enquanto presidente do Tiro 31, Fernando Luís Osório, em seu relatório de 1916, relatava:

\begin{abstract}
Com pleno êxito, corporifiquei a idéia, lançada em meu discurso de posse a esta presidência, da instalação em nossa sede de uma biblioteca cívica, para a qual, em correspondência ao apelo formulado, foram solicitamente ofertadas vultuosas obras de interesse pátrio, constantes do respectivo livro de registro (OSÓRIO, 1916, p. 06).
\end{abstract}

Em diversos momentos de seus escritos, Fernando Luís Osório abordou questões pertinentes à educação, e muitas vezes seus alicerces estavam embasados em autores uruguaios. Na obra Função hodierna das bibliotecas populares, o autor, além de salientar o papel fundamental das bibliotecas, frisa a enorme importância da relação destas com as escolas. "Ensinar às crianças o uso da biblioteca é já o tema que se inscreve, invariavelmente, no programa dos primeiros anos de estudo das escolas elementares, todas possuindo bibliotecas ao nível e gosto da petizada" (OSÓRIO, 1920, p. 13).

\footnotetext{
${ }^{11}$ Fernando Luis Osório nasceu em Pelotas, em 03 de novembro de 1886, falecendo no Cassino,em 25 de fevereiro de 1939. Bacharel pela Faculdade de Direito do Rio de Janeiro (1910). Advogado e catedrático de Teoria Geral de Direito da Faculdade de Direito de Pelotas. Fundador e diretor da Escola Prática de Comércio. Professor do Ginásio Pelotense. Diretor da Escola de Artes, Ofícios de Pelotas. Presidente da Biblioteca Pública Pelotense. Teve ativa participação nos meios culturais e educacionais, na cidade de Pelotas.
} 
Em sua concepção, as bibliotecas, além de parte essencial na organização do ensino, tinham como finalidade: permitir o acesso dos estudantes à livre escolha dos livros, proporcionar empréstimo de livros aos professores por um mês, no período das férias, etc. Parte de suas análises encontra-se ancorada, conforme o próprio autor explicita, no texto publicado no La Razon, de Montevidéu, edição de 3 de abril de 1920, Biblioteca para niños, voltada para desenvolver o gosto pela leitura e o hábito de frequentar as bibliotecas públicas.

Nessa mesma obra, expunha um vasto programa, no qual, entre outras questões, deveriam ser promovidas conferências educativas; intercâmbio de livros e aproximações de autores brasileiros e sul-americanos; incorporação da biblioteca à instrução geral, fazendo-a entrar no plano de educação (OSÓRIO, 1920, p. 17).

Infelizmente, a vasta biblioteca de Fernando Luís Osório foi parcialmente destruída, seja por descaso, seja pela umidade. Contudo, apesar disso, diversos exemplares acabaram sendo vendidos pelos seus descendentes às livrarias de livros usados, tornando possível a localização de alguns, entre estes, tem-se conhecimento das seguintes obras de autores uruguaios: Carlos Vaz Ferreira, Lecciones sobre Pedagogía y cuestiones de enseñanza (con aplicación a la secundario-preparatoria). Volumen III. Enseñanza Secundaria: Parte General. Montevidéo, Talleres Gráficos A. Barreiro y Ramos, 1918; Anales de Instrucción Primaria, Tomo I (3), 1903; Tomo I (4), 1903; Tomo II $(8,9,10), 1904$; Tomo II (11), 1905. Os dois primeiros exemplares, editados pela Talleres A. Barreiro y Ramos, e os dois últimos, pela Tipografia de la Escuela Nacional de Artes y Oficios.

Outras bibliotecas e entidades culturais (caso do Clube Caixeral e Biblioteca Pública Pelotense) possuíam acervos nos quais em seus catálogos constavam obras de intelectuais do Uruguai: Antero Urioste, Bibliotecas Escolares Populares, Montevidéo, Talleres Gráficos A. Barreiro y Ramos, 1923; Cátedra Escolar (Director: Profesor Juan B. Defféminis). Año 6으, Montevidéo, 15 de Junio de 1921, no 133; Memoria correspondiente a los años 1911 a 1914, inclusives, presentada a la Dirección General de Instrucción Primaria y al Ministerio de Instrucción Pública por el Doctor Abel J. Pérez, Inspector Nacional, Montevidéo, Talleres Gráficos A. Barreiros y Ramos, 1916.

De certo modo, esses diversos intelectuais atuavam na busca de uma transformação da sociedade, sendo que um dos veículos para divulgarem seus saberes era a imprensa, além de conferências. Políticos, advogados, professores, escritores tiveram grande contribuição na divulgação de ideias, muitas decorrentes do frequente contato com o Uruguai. Em suas obras, em seus discursos, em suas manifestações, é possível evidenciar indícios dessa influência. Em suas bibliotecas, os autores uruguaios perfilavam ao lado de autores nacionais, franceses, portugueses e, por consequência, os ecos de suas vozes reverberavam nos intelectuais pelotenses.

\section{CONSIDERAÇõES FINAIS}

Este texto tem como propósito discutir os itinerários de formação dos intelectuais de Pelotas, as redes de sociabilidade que engendraram suas projeções, bem como a influência de autores uruguaios nas suas formações e trajetórias. Assim, demonstra-se que, nas primeiras décadas do século $\mathrm{XX}$, era perceptível a configuração em Pelotas de diversos homens de letras, professores, escritores, jornalistas, poetas, que das mais variadas formas preocupavam-se em divulgar, discutir e propor projetos educacionais. Fosse por meio de redes de sociabilidade (associações culturais, clubes literários, bibliotecas, livrarias) ou por conferências, debates, cursos, aulas, artigos jornalísticos, dando expressão de suas posições enquanto intelectuais e formadores de opinião.

Pelo exposto, é possível evidenciar que tanto no Uruguai quanto no Rio Grande do Sul, no início do século $\mathrm{XX}$, houve acirradas disputas ideológicas entre diversos segmentos que buscavam, no campo educacional, dominar as estruturas de poder. No caso do Rio Grande do Sul, dois grupos são facilmente detectados: a Igreja Católica e seus opositores. Sendo que, entre estes, encontram-se forças de várias matizes, especialmente os positivistas, os liberais, os maçons e os anarquistas.

$\mathrm{O}$ processo de secularização uruguaio, fortemente estatal, cujos resultados mais notórios foram a privatização do religioso e a implantação gradual de uma religião civil laicizada, pretendia também definir os conflitos latentes sobre o ensino. Desse modo, configurou-se um debate em que polemizaram, de um lado, liberais anticlericais, promotores do "monopólio estatal da educação", que privilegiavam as vias institucionais para fazê-lo; e, do outro lado, os católicos, que tendo como bandeira a "liberdade de ensino" defendiam a iniciativa privada e religiosa da educação, "[...] intentando salvaguardar un espacio público ante el fuerte avance del proceso de secularización en la sociedad uruguaya" (GREISSING, 2000, p. 69).

Os intelectuais pelotenses mencionados neste texto possuíam fortes vínculos com o positivismo. Acreditavam que havia a necessidade de superar o ideário da Igreja Católica, na época dominada por uma cosmovisão ultramontanista (defendiam uma aproximação maior com o papa), em detrimento de um estreitamento de laços mais forte com o Estado Laico.

Desse modo, com este trabalho centrado em alguns intelectuais da cidade de Pelotas, é possível evidenciar 
a influência que diversos escritores/autores do Uruguai tiveram nas suas trajetórias.

\section{REFERÊNCIAS}

ALMANAQUE DE PELOTAS. Direção Ferreira \& C. Pelotas, 1916.

ALMANAQUE DE PELOTAS. Direção Ferreira \& C. Pelotas, 1918.

ALMANAQUE DE PELOTAS. Direção de F. Paradeda. Pelotas, 1933.

ARAÚJO, Orestes. Historia de la Escuela Uruguaya. Montevideo: Imp. El Siglo Ilustrado, 1911.

BORGES, Luis. O projeto cívico-pedagógico de João Simões Lopes Neto. Pelotas: Editora da Universidade Federal de Pelotas, 2009 [Dissertação de Mestrado].

BRALICH, Jorge. Breve historia de la educación en el Uruguay. Montevideo: Ediciones del Nuevo Mundo, 1987.

CAETANO, Gerardo. La República Batllista. Tomo 1. Ciudadanía, republicanismo y liberalismo en Uruguay (1910-1933). Montevideo: Ediciones de la Banda Oriental, 2011.

CAMPOS, Humberto de. Fragmentos de um diário. São Paulo: Editora Mérito, 1962.

CARVAlHO, Marta M. Chagas de Carvalho. A escola e a República. São Paulo: Editora Brasiliense, 1989.

CELLARD, André. A análise documental. In: POUPART, Jean et. al. A pesquisa qualitativa: enfoques epistemológicos e metodológicos. Petrópolis: Vozes, 2010.

DEVOTO, Juan E. Pivel; DEVOTO, Alcira Ranieri de Pivel. Historia de la Republica del Uruguay (1830-1930). 2. ed. Montevideo: Editorial Medina, 1956.

DINIZ, Carlos Sica. João Simões Lopes Neto, uma biografia. Porto Alegre: AGE, 2003.

GREISSING, Carolina. Conflictos y tensiones en el debate por la educación durante el Centenario (1910-1934). In: CAETANO, Gerardo. Los uruguayos del Centenario: nación, ciudadanía, religión y educación (1910-1930). Montevideo: Ediciones de la Banda Oriental, 2000.

MARLETTI, Carlo. Intelectuais (verbete). In: BOBBIO, Norberto; MATTEUCCI, Nicola; PASQUINO, Gianfranco. Dicionário de Política. 4. ed. Brasília: Universidade de Brasília, 1992.

MICHEL, Caroline B.; ARRIADA, Eduardo. Uma missão pedagógica ao Uruguai em 1913: uma leitura sob a ótica do jornal A Federação. In: ANPED SUL, X., 2013, Florianópolis, SC. Anais... Florianópolis: Udesc, 2013. p. 1-19. Disponível em: <http://xanpedsul.faed.udesc.br/arq_pdf/1211-0.pdf>. Acesso em: 03 jan. 2017.

MIGNOT, Ana Chrystina Venâncio; GONDRA, José Gonçalves. (Org.). Viagens pedagógicas. São Paulo: Cortez, 2007.

MIGNOT, Ana Chrystina Venâncio. Viajar para legitimar: Armanda Álvaro Alberto na Comissão de Intercâmbio BrasilUruguai (1931). In: Revista Brasileira de História da Educação, Campinas (SBHE/Autores Associados), n. 22, jan./ abr. 2010.
MUNICÍPIO DE PELOTAS. Relatório apresentado ao Conselho Municipal em 20 de setembro de 1911, pelo intendente José Barboza Gonçalves. Pelotas: Of. do Diário Popular, 1911.

NAGLE, Jorge. Educação e sociedade na Primeira República. 2. ed. Rio de Janeiro: DP\&A, 2001.

NAHUM, Benjamín. Breve historia del Uruguay independiente. Montevideo: Ediciones de la Banda Oriental, 2013.

ODDONE, Juan A. A formação do Uruguai moderno (18701930). In: BETHELL, Leslie (Org.). História da América Latina. De 1870 a 1930. São Paulo: Edusp, 2008. v. 5.

OLIVEIRA, Lúcia Lippi de. A questão nacional na Primeira República. São Paulo: Brasiliense, 1990.

OSÓRIO, Fernando Luiz. Tiro brasileiro. Discurso proferido no ato da posse de presidente do Tiro Brasileiro de Pelotas, no 31 da Confederação, em 2 de janeiro de 1916. Pelotas: Typ. do Diário Popular, 1916.

OSÓRIO, Fernando Luiz. Funcção hodierna das bibliothecas populares. Conferência inaugural da série de palestras com o povo, organizada pela Biblioteca Pública Pelotense. Pelotas: Typ. da Livraria Universal, 1920.

OSÓRIO, Fernando Luiz. O encanto dos salões: sua influência literária, artística, social e moral. O dom da raça. A sociedade rio-grandense. Linha-ideal de Pelotas. Pelotas: Livraria do Globo, 1931.

OSORIO, Joaquim Luis. Relatório [da] Sociedade de Tiro Brasileiro de Pelotas, no 31 da Confederação de Tiro Brasileiro. Pelotas: Livraria Universal de Echenique \& C., 1910 (impr. a vapor).

PALOMEQUE, Agapo Luis. La educación primaria entre 1886 y 1900. In: PALOMEQUE, Agapo Luis (Org.) Historia de la educación uruguaya: la educación uruguaya 1886-1930. Montevidéu: Ediciones de La Plaza, 2012. p. 25-58. (Colección Ensayos, 3).

PERES, Eliane. A escola graduada no Rio Grande do Sul no início do século XX: a implantação de um novo modelo e de uma nova cultura escolar. In: VIDAL, Diana Gonçalves; SCHWARTZ, Cleonara Maria (Org.). História das culturas escolares no Brasil. Vitória: Edufes, 2010.

RELATÓRIO apresentado ao Sr. Dr. A. A. Borges de Medeiros, presidente do Estado do Rio Grande do Sul, pelo Dr. Protásio Antônio Alves, secretário de Estado dos Negócios do Interior e Exterior. Em 8 de setembro de 1913. Porto Alegre: Officinas Graphicas da Livraria do Globo, 1913.

REVERBEL, Carlos. Um capitão da Guarda Nacional. Vida e obra de J. Simões Lopes Neto. Porto Alegre: Martins Livreiro, 1981.

ROCHA, Artur Pinto da. João Simões (Serafim Bemol). A Opinião Pública, Pelotas, 13 jul. 1916.

ROSA, Abadie Farias. Pelotas de Agora. In: Almanach de Pelotas. Pelotas: Gráfica do Diário Popular, 1918. p. 180.

SOUZA, Marcos Alves de. A cultura política do "batllismo" no Uruguai (1903-1958). São Paulo: Annablume, Faspesp, 2003.

SOUZA, Rosa Fátima de. História da organização do trabalho escolar e do currículo no século XX (ensino primário e secundário no Brasil). São Paulo: Cortez, 2008. 
VELlinhO, Moysés. A carreira póstuma de Simões Lopes Neto. Ensaios literários. Carlos Alexandre Baumgarten (Org.). Porto Alegre: IEL/Corag, 2001.

VIEIRA, Carlos Eduardo. Erasmo Pilotto: identidade, engajamento político e crenças dos intelectuais vinculados ao campo educacional brasileiro. In: LEITE, Juçara Luzia; ALVES, Cláudia (Org.). Intelectuais e história da educação no Brasil: poder, cultura e políticas. Vitória: Sociedade Brasileira de
História da Educação/Universidade Federal do Espírito Santo, 2011.

Recebido em 07.11.2016

Aprovado em 12.06.2018.

Endereço para correspondência:

Eduardo Arriada

Dom Pedro II, 414 - Centro

96010-300 Pelotas, RS, Brasil 